\title{
Electrical stimulation of renal nerves for modulating urine glucose excretion in rats
}

Ahmad A. Jiman ${ }^{1,2}$, Kavaljit H. Chhabra ${ }^{3}$, Alfor G. Lewis ${ }^{4}$, Paul S. Cederna ${ }^{1,5}$, Randy J. Seeley ${ }^{4}$, Malcolm J. Low ${ }^{3}$ and Tim M. Bruns ${ }^{1,2^{*}}$ (D)

\begin{abstract}
Background: The role of the kidney in glucose homeostasis has gained global interest. Kidneys are innervated by renal nerves, and renal denervation animal models have shown improved glucose regulation. We hypothesized that stimulation of renal nerves at kilohertz frequencies, which can block propagation of action potentials, would increase urine glucose excretion. Conversely, we hypothesized that low frequency stimulation, which has been shown to increase renal nerve activity, would decrease urine glucose excretion.

Methods: We performed non-survival experiments on male rats under thiobutabarbital anesthesia. A cuff electrode was placed around the left renal artery, encircling the renal nerves. Ureters were cannulated bilaterally to obtain urine samples from each kidney independently for comparison. Renal nerves were stimulated at kilohertz frequencies $(1-50 \mathrm{kHz})$ or low frequencies $(2-5 \mathrm{~Hz})$, with intravenous administration of a glucose bolus shortly into the 25-40-min stimulation period. Urine samples were collected at 5-10-min intervals, and colorimetric assays were used to quantify glucose excretion and concentration between stimulated and non-stimulated kidneys. A KruskalWallis test was performed across all stimulation frequencies $(a=0.05)$, followed by a post-hoc Wilcoxon rank sum test with Bonferroni correction $(a=0.005)$.
\end{abstract}

Results: For kilohertz frequency trials, the stimulated kidney yielded a higher average total urine glucose excretion at $33 \mathrm{kHz}(+24.5 \% ; n=9)$ than $1 \mathrm{kHz}(-5.9 \% ; n=6)$ and $50 \mathrm{kHz}(+2.3 \% ; n=14)$. In low frequency stimulation trials, $5 \mathrm{~Hz}$ stimulation led to a lower average total urine glucose excretion $(-40.4 \% ; n=6)$ than $2 \mathrm{~Hz}(-27.2 \% ; n=5)$. The average total urine glucose excretion between $33 \mathrm{kHz}$ and $5 \mathrm{~Hz}$ was statistically significant $(p<0.005)$. Similar outcomes were observed for urine flow rate, which may suggest an associated response. No trends or statistical significance were observed for urine glucose concentrations.

Conclusion: To our knowledge, this is the first study to investigate electrical stimulation of renal nerves to modulate urine glucose excretion. Our experimental results show that stimulation of renal nerves may modulate urine glucose excretion, however, this response may be associated with urine flow rate. Future work is needed to examine the underlying mechanisms and identify approaches for enhancing regulation of glucose excretion.

Keywords: Electrical stimulation, Kidney, Renal nerve, Glucose, Urine, Glycosuria

\footnotetext{
* Correspondence: bruns@umich.edu

${ }^{1}$ Department of Biomedical Engineering, University of Michigan, Ann Arbor,

MI, USA

${ }^{2}$ Biointerfaces Institute, University of Michigan, Ann Arbor, MI, USA

Full list of author information is available at the end of the article
}

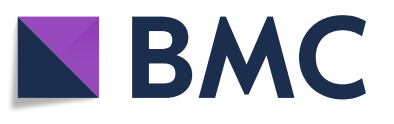

(c) The Author(s). 2018 Open Access This article is distributed under the terms of the Creative Commons Attribution 4.0 International License (http://creativecommons.org/licenses/by/4.0/), which permits unrestricted use, distribution, and reproduction in any medium, provided you give appropriate credit to the original author(s) and the source, provide a link to the Creative Commons license, and indicate if changes were made. The Creative Commons Public Domain Dedication waiver (http://creativecommons.org/publicdomain/zero/1.0/) applies to the data made available in this article, unless otherwise stated. 


\section{Background}

Diabetes mellitus is a chronic progressive disease that requires continuous monitoring and medical care to prevent the development of severe complications (American Diabetes Association (ADA) 2018). Medications for diabetic management are numerous and have different mechanisms of action (Chatterjee and Davies 2015). Recently, sodium-glucose co-transporter 2 (SGLT-2) inhibitors were approved by the US Food and Drug Administration (FDA) for patients with type 2 diabetes. SGLT-2 inhibitors prevent the activity of SGLT-2 transporters in the renal proximal tubule, thereby reducing glucose reuptake by the kidneys and increasing glucose excretion into urine (Lew and Wick 2015). Despite the progress in the development of diabetic medications, many lose their effectiveness over time, which makes achieving blood glucose control targets difficult for many diabetic patients (Blak et al. 2012; Khunti et al. 2013; Ali et al. 2013). Furthermore, sustained patient adherence to these diabetic medications in a lifelong therapy is a major challenge (García-Pérez et al. 2013; Sabaté 2003). Therefore, there is a crucial need for alternative diabetic therapies that overcome these pharmaceutical limitations.

In recent years, a global interest has emerged for catheter-based renal denervation as a potential treatment for drug-resistant hypertension (Pan et al. 2015; Bhatt et al. 2014). Early clinical trials of renal denervation showed significant blood pressure improvements (Esler et al. 2010; Krum et al. 2009). Interestingly, renal denervation was also associated with significant decreases in blood glucose levels (Mahfoud et al. 2011; Witkowski et al. 2011). Renal denervation studies in animals align with the observed blood glucose control improvements reported in clinical trials (Rafiq et al. 2015; Iyer et al. 2016). Furthermore, a recent study reported that mutant (neuronal POMC-deficient) mice showed improved capability for tolerating high blood glucose levels by exaggerating urine glucose excretion (glycosuria) compared to wild-type mice at similar induced blood glucose concentrations (Chhabra et al. 2016). A following study determined that the observed glycosuria and improved glucose tolerance were a result of reduced activity in renal sympathetic nerves (Chhabra et al. 2017). A non-pharmaceutical and reversible approach that has emerged in recent years for reducing nerve activity is kilohertz frequency stimulation, which has demonstrated nerve conduction block on multiple types of nerves (Kilgore and Bhadra 2014; Joseph and Butera 2009; Joseph and Butera 2011). We hypothesized that kilohertz frequency stimulation $(1-50 \mathrm{kHz})$ on renal nerves would attain similar results to renal denervation and induce urine glucose excretion.

Several studies have successfully influenced renal nerve activity in humans and animals by applying electrical stimulation. Electrical stimulation of renal nerves with an intra-arterial catheter electrode demonstrated increased blood pressure, and was considered as a method for locating suitable renal denervation targets for the treatment of drug-resistant hypertensive patients (Chinushi et al. 2013; Madhavan et al. 2014; Gal et al. 2015). Direct stimulation of renal nerves in rats using wire hook electrodes at low frequencies $(0.5-10 \mathrm{~Hz})$ showed increased renin secretion and water reabsorption, and decreased renal blood flow and sodium excretion responses (DiBona and Kopp 1997; DiBona and Sawin 1982; Bello-Reuss et al. 1976; Hermansson et al. 1981; Van Vliet et al. 1991). Sodium and glucose reabsorption are partially associated due to the presence of sodium-glucose co-transporters (SGLTs) in the renal proximal tubule (Mather and Pollock 2011). Our hypothesis was that direct stimulation of renal nerves at low frequencies $(0.5-10 \mathrm{~Hz})$ would decrease urine glucose excretion.

Therapies that directly alter neural activity (neuromodulation) are commonly prescribed as treatments for a variety of conditions (Krames et al. 2009; Famm et al. 2013). Gastric electrical stimulation is used to help patients with delayed stomach-emptying of solid foods (gastroparesis), which is commonly observed in patients with diabetes (Abell et al. 2003). Vagal nerve block (vBloc) therapy was recently approved by the FDA for certain patients with morbid obesity (Apovian et al. 2017). Clinical trials on vBloc therapy reported improvements in blood glucose control for patients with obesity and type 2 diabetes but were not sustained after 24 months (Herrera et al. 2017). Despite the success of neuromodulation therapies, to our knowledge, no clinical studies have investigated organ-targeted neuromodulation as a treatment approach for diabetes. In this study, we investigated modulation of urine glucose excretion with kilohertz and low frequency stimulation on renal nerves.

\section{Methods}

All experimental procedures were approved by the University of Michigan Institutional Animal Care and Use Committee (IACUC).

\section{Animals and housing}

Rats have a similar urinary system to humans and rat renal nerves have been visualized by several research groups (Stocker and Muntzel 2013; Miki et al. 2002). Non-survival, anesthetized experiments were performed on 24 male 290-550 g Long-Evans and Sprague-Dawley rats (Charles Rivers Laboratories, Wilmington, MA, USA). All animals were housed in ventilated cages under controlled temperature, humidity, and photoperiod (12-h light/dark cycle). The animals were provided with 
laboratory chow (5L0D, LabDiet, St. Louis, MO, USA) and tap water ad libitum.

\section{Experimental preparation}

For anesthesia, a single dose of thiobutabarbital sodium salt hydrate (Inactin, T133-1G, Sigma-Aldrich Corp., St. Louis, MO, USA) was injected intraperitoneally $(110 \mathrm{mg} /$ $\mathrm{kg} \mathrm{BW})$. Thiobutabarbital is commonly used in renal studies and is known to preserve renal function during anesthesia (Walter et al. 1989; Sohtell et al. 1983). Rats were placed on a heating pad (ReptiTherm, Zoo Med Laboratories Inc., San Luis Obispo, CA, USA) and temperature was monitored through a rectal temperature sensor (SurgiVet, Smiths Medical, Norwell, MA, USA). Under a dissection microscope (Lynx EVO, Vision Engineering Inc., New Milford, CT, USA), a midline cervical incision was made and the jugular vein was cannulated with polyethylene tubing (BTPE-50, Instech Laboratories Inc., Plymouth Meeting, PA, USA). Through the jugular vein, $0.9 \% \mathrm{NaCl}$ (saline), equivalent to $10 \%$ body weight, was infused over $30 \mathrm{~min}$, and then followed by a continuous infusion of $0.2 \mathrm{~mL} / \mathrm{min}$ using a syringe pump (NE-1000, New Era Pump Systems Inc., Farmingdale, NY, USA) (Bello-Reuss et al. 1976). A tracheotomy was performed to ensure a clear airway. Ureters were cannulated bilaterally with polyethylene tubing (BTPE-10, Instech Laboratories Inc., Plymouth Meeting, PA, USA) to obtain urine samples from each kidney independently. The left kidney was exposed through a midline abdominal incision. Fat and connective tissue surrounding the kidney were separated using cotton-tipped applicators to further expose the kidney and renal artery. A bipolar nerve cuff electrode (1.00 mm inner-diameter, $100 \mu \mathrm{m}$ platinum contacts, Microprobes for Life Science, Gaithersburg, MD, USA) was placed around the renal artery, encircling renal nerves that run along the artery (Stocker and Muntzel 2013; Miki et al. 2002). Care was taken to not damage the renal nerve branches and to not occlude blood flow in the renal artery. To ensure that the renal nerves were intact, biphasic stimulation pulses at $10 \mathrm{~Hz}, 10 \mathrm{~V}$ were applied for approximately $1 \mathrm{~min}$ through the nerve cuff electrode. This resulted in temporary kidney ischemia, which was confirmed by the observation of kidney surface blanching (Hermansson et al. 1981; Yao et al. 2014). This stimulation-driven ischemia occurred in all the experiments in which we performed the test $(n=18)$. Prior to implant, electrode impedance measurements $(4.77 \pm 1.53$ $\mathrm{k} \Omega$ ) were taken using an impedance tester (nanoZ, White Matter LLC, Seattle, WA, USA) at $1 \mathrm{kHz}$ in saline to confirm functionality of the nerve cuff electrode.

\section{Electrical stimulation}

The nerve cuff electrode placed on the renal nerves was connected to an isolated pulse stimulator (Model 4100,
A-M Systems, Loop Sequim, WA, USA). For kilohertz frequency stimulation, a function generator (33220A, Agilent Technologies, Santa Clara, CA, USA) was connected to the isolated pulse stimulator to generate sinusoidal waveforms at 1,33 or $50 \mathrm{kHz}$. The stimulation amplitude was fixed at $15 \mathrm{~V}$, which has been shown to provide nerve conduction block for all selected frequencies on unmyelinated nerves (Joseph and Butera 2009; Joseph and Butera 2011). For low frequency stimulation, the isolated pulse stimulator generated biphasic pulses at 2 or $5 \mathrm{~Hz}$. The stimulation amplitude and pulse width was fixed at $10 \mathrm{~V}$ and $0.5 \mathrm{msec}$, respectively, which is above the activation threshold for rat C-fibers using cuff electrodes (Woodbury and Woodbury 1990). The stimulation frequencies were randomly ordered between trials across all experiments to mitigate sequential effects.

\section{Experimental protocol}

After completion of surgery, a stabilization period of 10-60 min was provided. In each experiment, 1-3 trials with different stimulation frequencies were applied on the nerve cuff electrode. Stimulation was applied at the start of a trial and remained on for $25-40 \mathrm{~min}$. To elevate blood glucose levels beyond the expected renal threshold for glucose excretion ( $400 \mathrm{mg} / \mathrm{dL}$ ) (Liang et al. 2012), a $0.30-1.00 \mathrm{~g}$ bolus dose of glucose (50\% Dextrose Injection USP, Hospira Inc., Lake Forest, IL, USA) was delivered through the jugular vein at 2-16 min into each trial. To confirm blood glucose increase and to monitor blood glucose levels over time, drops of blood $(<0.1 \mathrm{~mL})$ from a tail cut were used to obtain blood glucose concentration measurements using a glucometer (AlphaTRAK 2, Abbott, Abbott Park, IL, USA) before glucose infusion and every 5-10 min after glucose infusion. Urine samples from each kidney were collected in pre-weighed sampling tubes (3448, Thermo Fisher Scientific, Waltham, WA, USA) at 5-10-min intervals. Ten minutes after the end of a trial, blood glucose measurements were expected to be around baseline levels. If not, a longer washout period was provided to the rat before proceeding to the next experimental trial. The collected urine samples were weighed on a scale (AE 160, Mettler Toledo, Columbus, OH, USA) for volume estimations $(1 \mu \mathrm{L} / \mathrm{mg})$. Urine glucose concentrations were measured using colorimetric assays (10009582, Cayman Chemical, Ann Arbor, MI, USA). The experimental setup and protocol timeline are summarized in Fig. 1.

From the urine sample volumes and glucose concentration measurements, the total urine glucose excretion (UGE) was calculated and compared between the stimulated and non-stimulated kidney $\left[\Delta \mathrm{UGE}=\left(\mathrm{UGE}_{\text {stimulated }}\right.\right.$ - $\left.\mathrm{UGE}_{\text {non-stimulated }} / \mathrm{UGE}_{\text {non-stimulated }} \times 100\right]$ for each trial. For urine glucose concentration (UGC) and urine flow rate (UFR), the area under the curve (AUC) was 


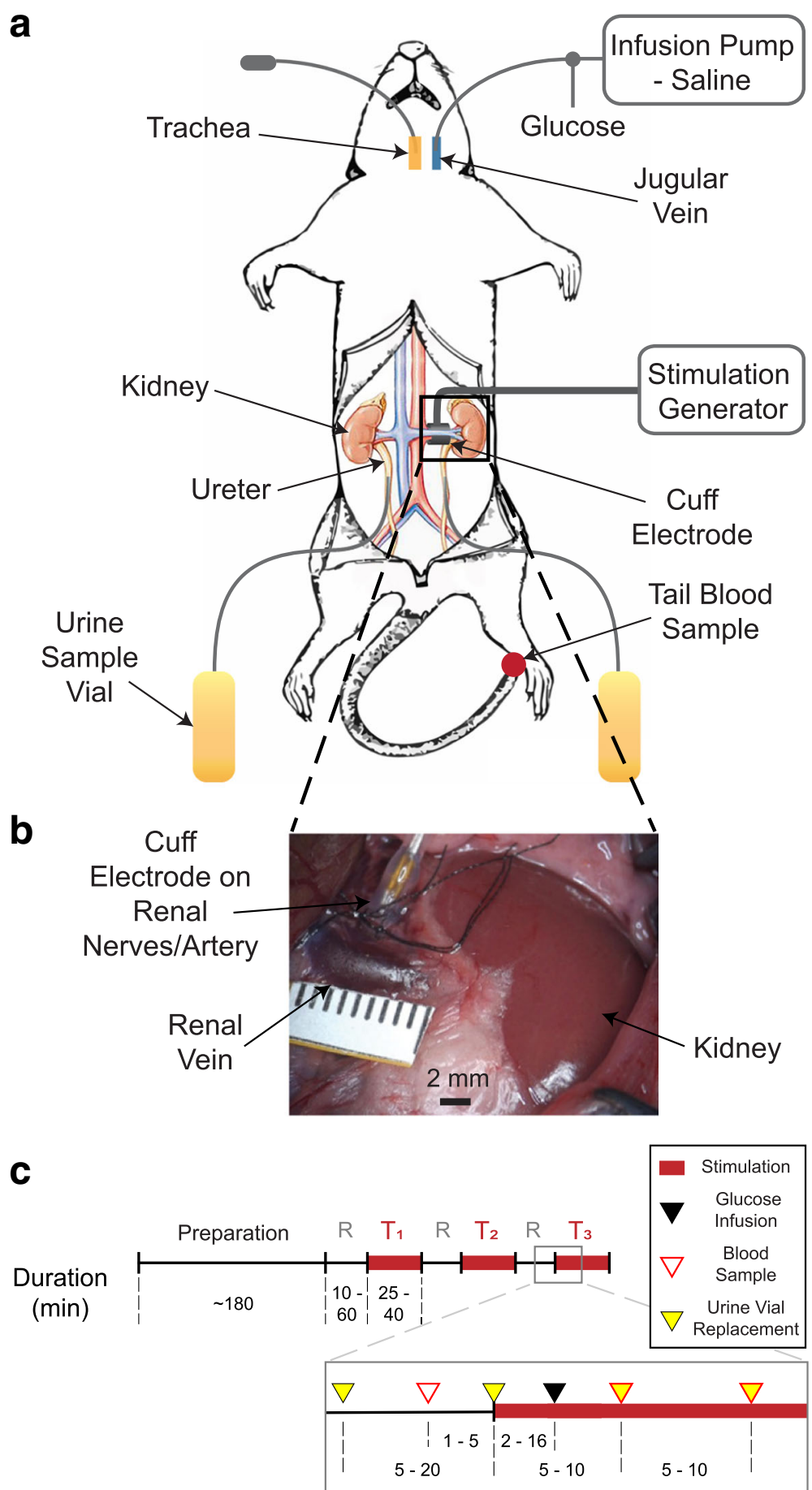

Fig. 1 Experimental setup diagram and protocol timeline. a Experimental setup: Jugular vein was cannulated for saline and glucose infusion. Nerve cuff electrode was placed on renal nerves of the left kidney and connected to a stimulation generator. Ureters were cannulated bilaterally, and urine samples were collected in sampling vials. b Nerve cuff electrode was placed around the renal artery, encapsulating the renal nerve branches that run along the renal artery. c Timeline for experimental protocol: Each experiment consisted of $1-3$ stimulation trials $\left(T_{1}-T_{3}\right)$, with a rest period (R) before each trial. A glucose bolus was infused in each trial. Blood glucose measurements and urine samples were obtained periodically throughout the trials

calculated for each trial by trapezoidal numerical integration and compared between the kidneys in a similar manner as UGE. From blood glucose concentration
(BGC) values, a BGC decrease rate (BGCDR) was obtained by calculating the linear regression slope of BGC values starting approximately $10 \mathrm{~min}$ after the glucose 
bolus infusion and ending with the final value in the trial. The glucometer was unable to read blood glucose concentrations above $750 \mathrm{mg} / \mathrm{dL}$, which occasionally occurred during the first $10 \mathrm{~min}$ after a glucose bolus infusion. Therefore, BGC values within $10 \mathrm{~min}$ after a glucose bolus infusion were excluded in BGCDR calculations for all stimulation trials.

\section{Statistical analysis}

Across all experiments, data sets did not follow a normal distribution (confirmed by one-sample Kolmogorov-Smirnov test). Therefore, a non-parametric Kruskal-Wallis test was performed to measure statistical significance across stimulation frequencies. Statistical significance was considered at $p$ $<0.05$. A two-sided Wilcoxon rank sum test was then applied between pairs of stimulation frequencies. The significance level $(\alpha)$ was adjusted according to a Bonferroni correction, where $\alpha$ was divided by the number of stimulation pairs (10). Thus, statistical significance for the Wilcoxon rank sum test was considered at $p<0.005$. All data analysis and statistical tests were performed using MATLAB software (R2014b, MathWorks, Natick, MA, USA).

\section{Results}

Across the 24 experiments on male rats, we performed stimulation trials at kilohertz frequencies $(1 \mathrm{kHz}[n=6]$, $33 \mathrm{kHz}[n=9]$ and $50 \mathrm{kHz}[n=14])$ and low frequencies
( $2 \mathrm{~Hz}[n=5]$ and $5 \mathrm{~Hz}[\mathrm{n}=6])$. We obtained measurements of urine glucose excretion, urine glucose concentration, urine flow rate, and blood glucose concentration in each trial.

\section{Urine glucose excretion}

Glucose excretion was analyzed and compared between the urine samples obtained from the stimulated and non-stimulated kidneys. The percentage difference of urine glucose excretion ( $\triangle \mathrm{UGE}$ ) between the stimulated and non-stimulated kidneys for all stimulation frequencies are shown in Fig. 2a. Overall, stimulation frequency had a statistically significant effect on $\triangle$ UGE (Kruskal-Wallis test, $p<0.05)$. In kilohertz frequency trials, $33 \mathrm{kHz}$ yielded a higher average $\Delta \mathrm{UGE}(+24.5 \% ; n=9)$ than $1 \mathrm{kHz}(-5.9 \% ; n=6)$ and $50 \mathrm{kHz}(+2.3 \% ; n=14)$. In low frequency trials, $5 \mathrm{~Hz}$ stimulation led to a lower average $\triangle$ UGE $(-40.4 \% ; \mathrm{n}=6)$ than $2 \mathrm{~Hz}(-27.2 \% ; n=$ $5)$. Statistical significance only occurred between the $\triangle \mathrm{UGE}$ of $33 \mathrm{kHz}$ and $5 \mathrm{~Hz}$ trials (Wilcoxon rank sum test, $p<0.005)$. Stimulation at kilohertz frequencies met our hypothesis of increased UGE in 14 trials (48.2\%), had no apparent effect $(|\Delta \mathrm{UGE}|<5 \%)$ in 10 trials (34.5\%), and showed a decrease in UGE in 5 trials (17.2\%) out of the 29 total kilohertz frequency trials. In low frequency stimulation trials, we observed a decrease of UGE in 9 trials (81.8\%), no apparent effect in 1 trial

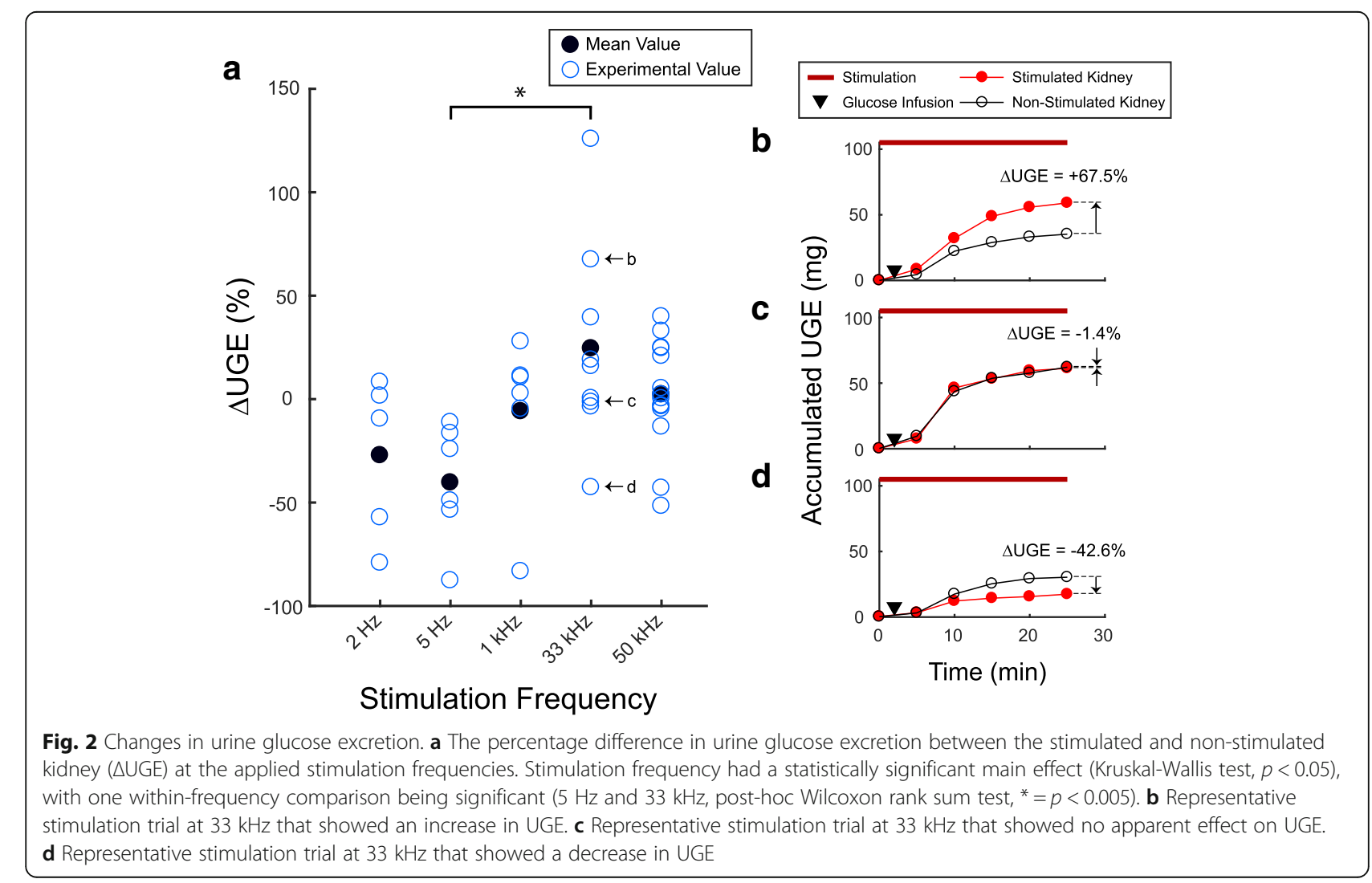


(9.1\%), and an increase of UGE in 1 trial (9.1\%) out of 11 trials in total. Examples of stimulation trials at $33 \mathrm{kHz}$ that displayed an increase, no apparent effect, or a decrease in UGE are shown in Fig. 2b-d.

\section{Urine glucose concentration}

The urine glucose concentration (UGC) differences between the urine samples obtained from the stimulated and non-stimulated kidneys at all stimulation frequencies are shown in Fig. 3a. The average UGC difference was $+5.9 \%$ at $2 \mathrm{~Hz}(n=5),+12.6 \%$ at $5 \mathrm{~Hz}(n=6),+3.7 \%$ at $1 \mathrm{kHz}(\mathrm{n}$ $=6),+3.7 \%$ at $33 \mathrm{kHz}(n=9)$, and $-6.2 \%$ at $50 \mathrm{kHz}(n=$ 14). Stimulation frequency did not have an overall significant effect on UGC (Kruskal-Wallis test, $p=0$. 2365).

\section{Urine flow rate}

The urine flow rate (UFR) differences between the urine samples obtained from the stimulated and non-stimulated kidneys at all stimulation frequencies are shown in Fig. 4a. The average UFR difference was $-27.7 \%$ at $2 \mathrm{~Hz}(n=5),-40.6 \%$ at $5 \mathrm{~Hz}(n=6),-6.0 \%$ at $1 \mathrm{kHz}$ $(n=6),+14.6 \%$ at $33 \mathrm{kHz} \quad(n=9)$, and $+9.8 \%$ at $50 \mathrm{kHz}(n=14)$. Stimulation frequency had a statistically significant main effect on UFR (Kruskal-Wallis test, $p<0.05$ ), with trials at $33 \mathrm{kHz}$ and $5 \mathrm{~Hz}$ significantly different from one another (post-hoc Wilcoxon rank sum test, $p<0.005$ ).

\section{Blood glucose concentration}

The blood glucose concentration decrease rates (BGCDRs) during stimulation at all frequencies are shown in Fig. $5 \mathrm{a}$. The average BGCDR was $-9.1 \mathrm{mg} / \mathrm{dL} / \mathrm{min}$ at $2 \mathrm{~Hz}(n=4)$, $-13.5 \mathrm{mg} / \mathrm{dL} / \mathrm{min}$ at $5 \mathrm{~Hz}(n=5),-13.5 \mathrm{mg} / \mathrm{dL} / \mathrm{min}$ at $1 \mathrm{kHz}(n=6),-12.0 \mathrm{mg} / \mathrm{dL} / \mathrm{min}$ at $33 \mathrm{kHz}(n=9)$, and $12.5 \mathrm{mg} / \mathrm{dL} / \mathrm{min}$ at $50 \mathrm{kHz}(n=13)$. No statistically significant main effect occurred across all stimulation frequencies (Kruskal-Wallis test, $p=0.4708)$. BGCDR at some stimulation trials $[2 \mathrm{~Hz}(n=1), 5 \mathrm{~Hz}(n=1)$ and $50 \mathrm{kHz}(n=1)]$ were not calculated due to insufficient BGC values.

\section{Discussion}

The aim of this study was to investigate modulation of urine glucose excretion by electrical stimulation of renal nerves. We hypothesized that stimulation of renal nerves at kilohertz frequencies $(1-50 \mathrm{kHz})$ would increase urine glucose excretion (UGE), while low frequency stimulation $(2-5 \mathrm{~Hz})$ would decrease UGE. Although stimulation at kilohertz frequencies did not always lead to an increase in UGE, $33 \mathrm{kHz}$ showed a notable average increase in UGE in accordance with our hypothesis. In contrast, low frequency stimulation typically showed a decrease in UGE, with the strongest effect observed at $5 \mathrm{~Hz}$ stimulation (Fig. 2). To our knowledge, this study is the first to demonstrate influence of electrical stimulation of renal nerves on glucose excretion.

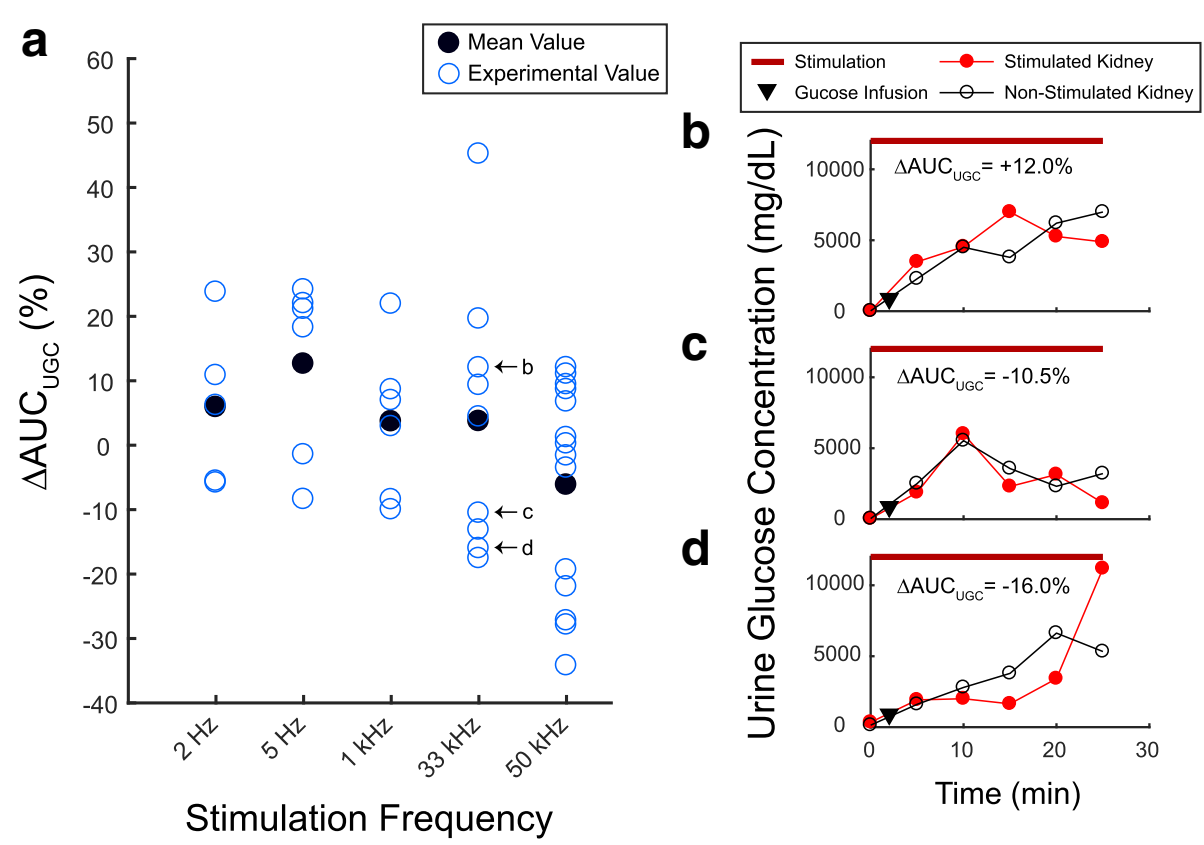

Fig. 3 Changes in urine glucose concentration. a The percentage difference between the area under the curve for urine glucose concentration of the stimulated and non-stimulated kidney ( $\triangle A \cup C_{U G C}$ ) at the applied stimulation frequencies. b Urine glucose concentration (UGC) measurements for the trial shown in Fig. 2b. c UGC measurements for the trial shown in Fig. 2c. d UGC measurements for the trial shown in Fig. 2d 

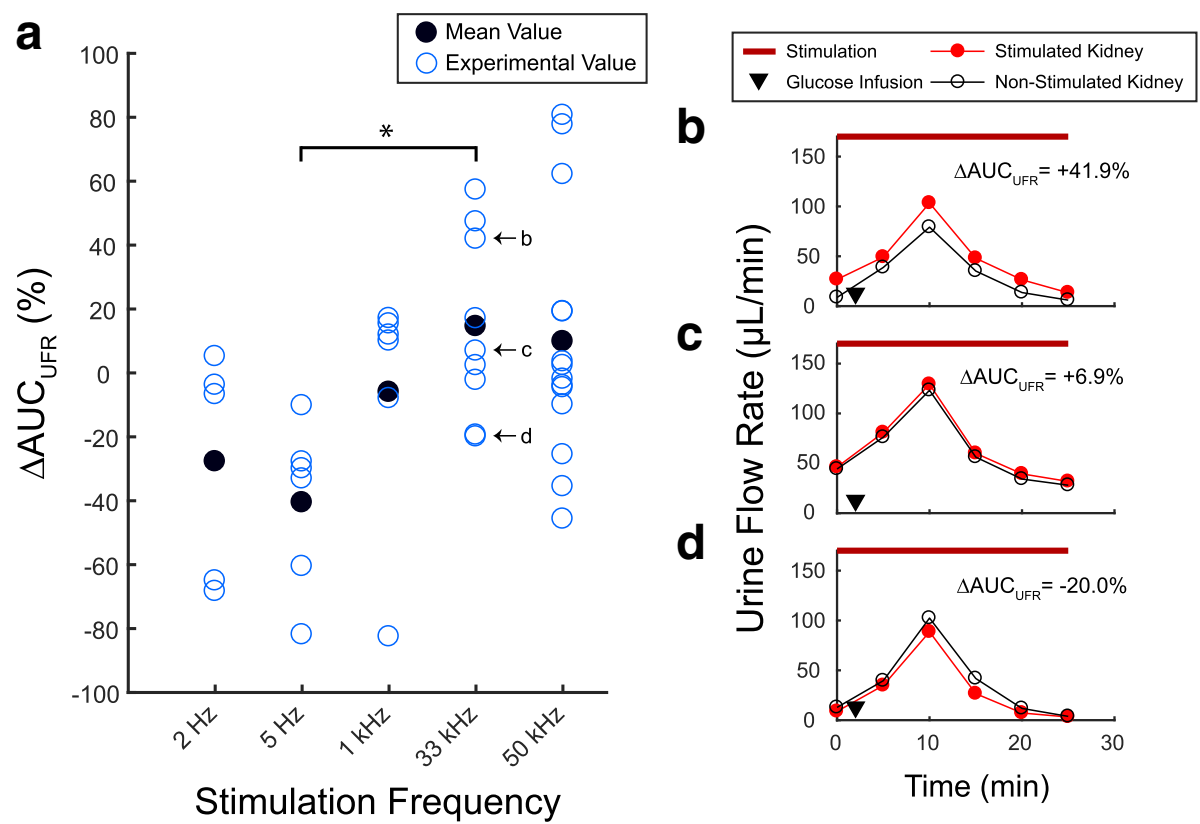

Fig. 4 Changes in urine flow rate. a The percentage difference between the area under the curve for urine flow rate of the stimulated and non-stimulated kidney $\left(\triangle A \cup C_{U F R}\right.$ ) at the applied stimulation frequencies. Stimulation frequency had a significant main effect (Kruskal-Wallis test, $p<0.05$ ), with $5 \mathrm{~Hz}$ and $33 \mathrm{kHz}$ trials significantly different from each other (post-hoc Wilcoxon rank sum test, ${ }^{*}=p<0.005$ ). b Urine flow rate (UFR) measurements for the trial shown in Fig. 2b. c UFR measurements for the trial shown in Fig. 2c. $\mathbf{d}$ UFR measurements for the trial shown in Fig. $2 d$
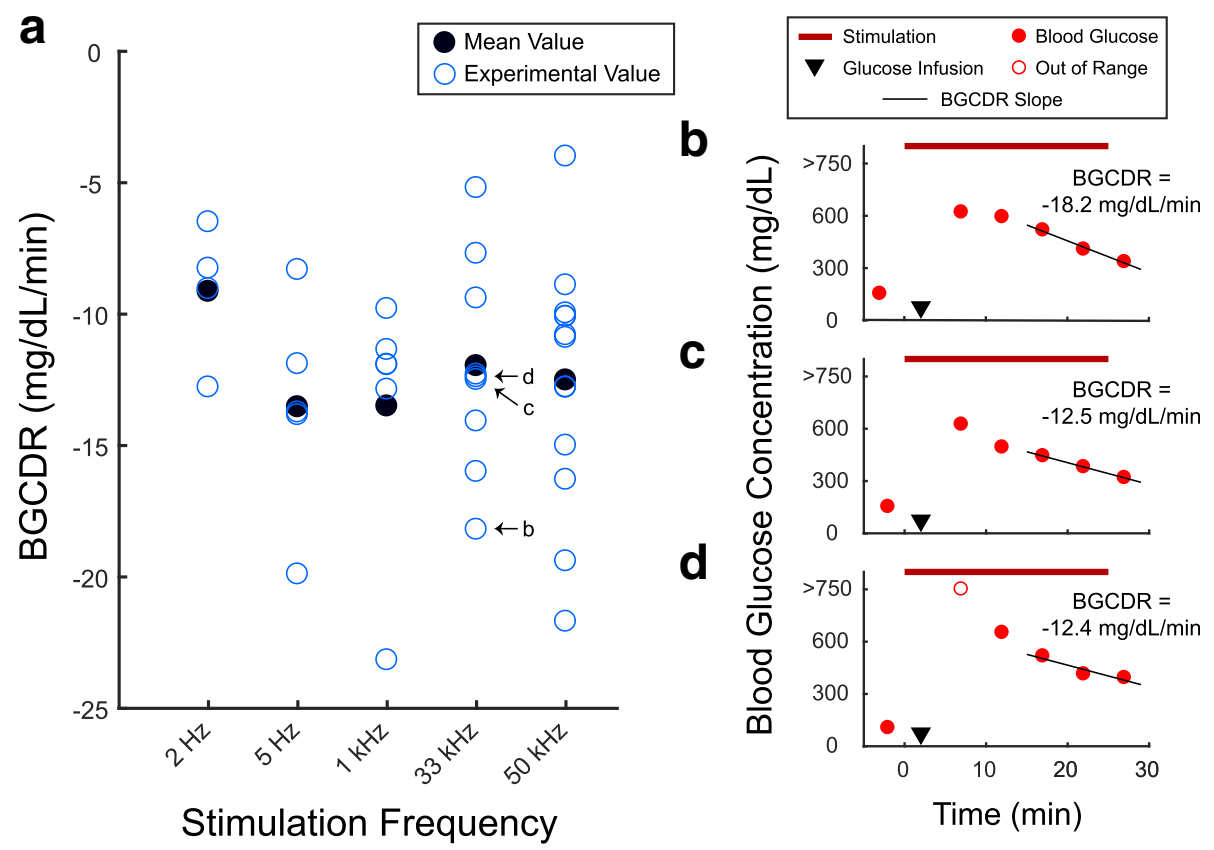

Fig. 5 Changes in blood glucose concentration. a The blood glucose concentration decrease rate (BGCDR) at the applied stimulation frequencies. b Blood glucose concentration (BGC) measurements and BGCDR (slope) for the trial shown in Fig. 2b. c BGC and BGCDR measurements for the trial shown in Fig. 2c. d BGC and BGCDR measurements for the trial shown in Fig. 2d. BGC measurements above 750 mg/dL were not available due to the limitations of the glucometer 
The average differences in UGE were similar to the average differences observed in urine flow rate (UFR), as shown in Fig. 4. This associated response may suggest that either UGE or UFR was the primary effect of stimulation, while the other was a secondary response. Previous studies that applied stimulation of renal nerves at low frequencies observed a $25-52 \%$ reduction in UFR (Bello-Reuss et al. 1976; Pontes et al. 2015). Those percentages align with the average reduction of UFR we observed at low frequency stimulation $(28 \%$ at $2 \mathrm{~Hz}$, $41 \%$ at $5 \mathrm{~Hz}$ ), suggesting that UFR may be the primary response of stimulation at low frequencies. On the other hand, we observed an increase in UFR at 33 and $50 \mathrm{kHz}$ stimulation. To our knowledge, no studies have reported an increase in UFR by stimulation of renal nerves. Although it is possible that changes in UFR may have directly led to corresponding changes in UGE, the primary response of UFR or UGE to stimulation at kilohertz frequencies cannot be determined in this study. UFR and UGE are normally associated, as increased urination is a common adverse event in diabetic patients treated with sodium-glucose co-transporter 2 (SGLT2) inhibitors that primarily increase urine glucose excretion (Seufert 2015; Wilding 2014). Additional studies are required to distinguish the glucose excretion and urine flow effects for stimulation of renal nerves.

Stimulation of renal nerves did not have a clear effect on urine glucose concentration (UGC), as no statistical significance occurred across stimulation frequencies (Fig. 3). Furthermore, we did not observe a clear difference between kilohertz or low frequency stimulation on the decrease rate for blood glucose concentration (BGC) after infusion of a glucose bolus (Fig. 5). Typically, BGC would reach a peak value within the first $10 \mathrm{~min}$ after glucose bolus infusion. Then, BGC values would gradually decrease and return to around baseline values at 30-40 min after the glucose infusion, regardless of the stimulation parameters. The variation in the sample size of the stimulation frequency groups may have also contributed to these unclear responses. Modifications and improvements in experimental design may be necessary to capture clear and consistent responses to stimulation of renal nerves.

Renal nerve branches are distributed around the renal artery in a plexus form. Ultrastructural studies using electron microscopy techniques have shown that renal nerve fibers innervate epithelial cells of proximal tubules, the glucose reabsorption region of the kidney (Mather and Pollock 2011; Muller and Barajas 1972; Luff et al. 1992). Although studies have examined the distribution of renal nerves around the renal artery (Maeda et al. 2014; Sakakura et al. 2014; van Amsterdam et al. 2016), we could not determine the renal nerve branches that innervate the proximal tubules in this study.
Therefore, we utilized a cuff electrode with the purpose of encircling all the renal nerve branches surrounding the renal artery. In order to place a cuff electrode, the renal artery was isolated by removing adjacent connective tissue that may have contained fine renal nerve branches. Although we ensured that the renal nerves were moderately intact by observing temporary kidney surface blanching at $10 \mathrm{~Hz}$ stimulation (Hermansson et al. 1981; Yao et al. 2014), the variations in connective tissue removal and relative shifts in the electrode placement along the renal artery across experiments may have contributed to the variability of our outcome results. This inconsistency in outcomes has also been observed in renal denervation studies, where conflicting results were reported in clinical studies (Bhatt et al. 2014; Mahfoud et al. 2011; Witkowski et al. 2011). The reported variability is suspected to be from variations in ablation locations across renal denervation procedures performed in multiple centers (Mahfoud et al. 2014). Experimental improvements in electrode placement and the plexus-electrode interface may be required to obtain more consistent results.

An anatomical analysis in rats showed that 96\% of renal nerve axons are unmyelinated C-fibers (DiBona et al. 1996). Although nerve conduction block experiments using kilohertz frequency stimulation have been typically performed using cuff electrodes encircling myelinated motor neurons while monitoring muscle tension for block validation (Kilgore and Bhadra 2014; Bhadra and Kilgore 2005), nerve block has also been demonstrated on purely unmyelinated fibers using suction electrodes and confirmed by direct recordings of action potential propagation (Joseph and Butera 2009). In this study, the amplitude of sinusoidal kilohertz frequency stimulation was fixed at $15 \mathrm{~V}$, which is expected to be above the threshold for nerve conduction block at the selected frequencies (Joseph and Butera 2011; Bhadra and Kilgore 2005; Patel and Butera 2015). On the other hand, previous studies increased renal nerve activity by low frequency stimulation (Bello-Reuss et al. 1976; DiBona 2000). The stimulation amplitude and pulse width in this study at low frequencies was consistent at $10 \mathrm{~V}$ and 0.5 msec, respectively, which is above the activation threshold for rat C-fibers using cuff electrodes (Woodbury and Woodbury 1990). However, to validate the true presence of nerve conduction block or increased neural activity, multiple recording and stimulating electrodes must be placed along the renal nerves. Unfortunately, this was difficult to accomplish in this study due to our limited ability to expose and isolate the renal nerves $(\sim$ 2-4 $\mathrm{mm}$ ), in addition to the anticipated noise contamination issues between adjacent stimulating and recording electrodes (Kilgore and Bhadra 2014). Additional experiments are required to examine the mechanism of action for stimulation of renal nerves. 
The work presented here was a feasibility study to investigate glucose excretion modulation by stimulation of renal nerves. There are numerous limitations to this study. Although changes in UGE were observed in response to stimulation of renal nerves, this study does not provide any evidence on the underlying mechanisms for these changes. It is unknown if the observed changes in UGE were a consequence of changes in UFR, or directly related to the gluconeogenesis process or the glucose transport pathways in the proximal tubules that are innervated by renal nerves (Mather and Pollock 2011; Muller and Barajas 1972; Luff et al. 1992). Measurements of renal function, such as glomerular filtration rate, renal plasma flow and sodium excretion (Toto 1995; Phillips and Hamilton 1948) were not obtained in this feasibility study. The assessment of renal function is an absolute necessity for the progression of this research. The large variation in the results of this study may have been due to multiple reasons. In addition to the variability in electrode placement, the unilateral stimulation approach in this study may have provoked reno-renal reflexes, where the non-stimulated kidney modifies its activity based on changes in the stimulated kidney (Zanchetti et al. 1984). The possible presence of these reflexes may have altered the outcomes of this study. Further experiments with reno-renal reflex elimination procedures, such as bilateral stimulation or denervation of non-stimulated kidneys, may be necessary to obtain unhindered stimulation outcomes.

Although further experiments are required to examine the underlying mechanisms for stimulation of renal nerves, this study may introduce a new approach for regulation of glucose excretion. Recently approved medications for patients with type 2 diabetes are SGLT-2 inhibitors, which prevent the activity of glucose transporters in the kidney and lead to increased glucose excretion into urine (Lew and Wick 2015). Stimulation of renal nerves may provide an alternative treatment approach for glycemic control that avoids patient compliance issues typically seen with medications (Polonsky and Henry 2016).

\section{Conclusion}

To our knowledge, this is the first study to investigate electrical stimulation of renal nerves to modulate urine glucose excretion. Our experimental results show that stimulation of renal nerves may modulate urine glucose excretion, however, this outcome may be associated with urine flow rate. Future work is needed to examine the underlying mechanisms and identify approaches for enhancing regulation of glucose excretion.

\section{Abbreviations}

AUC: Area under the curve; BGC: Blood glucose concentration; BGCDR: Blood glucose concentration decrease rate; UFR: Urine flow rate; UGC: Urine glucose concentration; UGE: Urine glucose excretion

\section{Acknowledgements}

The authors thank Eric Kennedy, Zachary Ricca, Christopher Stephan, Shani Ross, Aileen Ouyang, Zachariah Sperry, and Lauren Zimmerman for their assistance with experimental preparation and protocol, Cynthia Chestek and Stephen Kemp for their expert advice, and Robert Kennedy, Alexandros Zestos and Jack Magrisso for their assistance with sample analysis.

\section{Funding}

This research was supported by a grant from the University of Michigan MCubed Program. The work of A. Jiman was also supported by the King Abdulaziz University Scholarship.

\section{Availability of data and materials}

The data generated during the current study and relevant MATLAB code are available in a repository on the Open Science Framework: https://osf.io/ w8mrp/. DOl: https://doi.org/10.17605/OSF.IO/W8MRP

\section{Authors' contributions}

Planned study - AJ, KC, AL, PC, RS, ML, TB. Performed surgeries and collected data - AJ, KC, AL, PC, TB. Analyzed data - AJ, KC, TB. Drafted manuscript AJ, TB. Reviewed manuscript and approved final version - AJ, KC, AL, PC, RS, $M L, T B$.

\section{Ethics approval}

All animal procedures were approved by the University of Michigan Institutional Animal Care and Use Committee (IACUC).

\section{Competing interests}

RJS has received research support from and/or has served as an advisor or consultant to Ethicon Endo-Surgery/Johnson \& Johnson, Orexigen, Novo Nordisk, Daiichi Sankyo, Janssen/Johnson \& Johnson, Novartis, Paul Hastings Law Firm, Zafgen, Medlmmune, Sanofi, Kallyope, and Scohia.

\section{Publisher's Note}

Springer Nature remains neutral with regard to jurisdictional claims in published maps and institutional affiliations.

\section{Author details \\ ${ }^{1}$ Department of Biomedical Engineering, University of Michigan, Ann Arbor, MI, USA. ${ }^{2}$ Biointerfaces Institute, University of Michigan, Ann Arbor, MI, USA. ${ }^{3}$ Department of Molecular and Integrative Physiology, University of Michigan, Ann Arbor, MI, USA. ${ }^{4}$ Department of Surgery, University of Michigan, Ann Arbor, MI, USA. ${ }^{5}$ Department of Surgery, Plastic Surgery Section, Michigan Medicine, Ann Arbor, MI, USA.}

Received: 18 March 2018 Accepted: 17 May 2018

Published online: 29 May 2018

\section{References}

Abell T, McCallum R, Hocking M, Koch K, Abrahamsson H, Leblanc I, et al. Gastric electrical stimulation for medically refractory gastroparesis. Gastroenterology. 2003;125:421-8.

Ali MK, Bullard KM, Saaddine JB, Cowie CC, Imperatore G, Gregg EW. Achievement of goals in U.S. diabetes care, 1999-2010. N Engl J Med. 2013; 368:1613-24. https://doi.org/10.1056/NEJMsa1213829.

American Diabetes Association. Standards of medical Care in Diabetes - 2018. Diabetes Care. 2018:41(Suppl 1):S1-159.

Apovian CM, Shah SN, Wolfe BM, Ikramuddin S, Miller CJ, Tweden KS, et al. Twoyear outcomes of vagal nerve blocking (vBloc) for the treatment of obesity in the ReCharge trial. Obes Surg. 2017;27:169-76. https://doi.org/10.1007/ s11695-016-2325-7.

Bello-Reuss E, Trevino DL, Gottschalk CW. Effect of renal sympathetic nerve stimulation on proximal water and sodium reabsorption. J Clin Invest. 1976; 57:1104-7.

Bhadra N, Kilgore KL. High-frequency electrical conduction block of mammalian peripheral motor nerve. Muscle Nerve. 2005;32:782-90.

Bhatt DL, Kandzari DE, O'Neill WW, D'Agostino R, Flack JM, Katzen BT, et al. A controlled trial of renal denervation for resistant hypertension. N Engl J Med. 2014;370:1393-401. https://doi.org/10.1056/NEJMoa1402670. 
Blak BT, Smith HT, Hards M, Maguire A, Gimeno VA. Retrospective database study of insulin initiation in patients with type 2 diabetes in UK primary care. Diabet Med. 2012;29:e191-8.

Chatterjee S, Davies MJ. Current management of diabetes mellitus and future directions in care. Postgrad Med J. 2015;91:612-21. https://doi.org/10.1136/ postgradmedj-2014-133200.

Chhabra KH, Adams JM, Fagel B, Lam DD, Qi N, Rubinstein M, et al. Hypothalamic POMC deficiency improves glucose tolerance despite insulin resistance by increasing glycosuria. Diabetes. 2016;65:660-72.

Chhabra KH, Morgan DA, Tooke BP, Adams JM, Rahmouni K, Low MJ. Reduced renal sympathetic nerve activity contributes to elevated glycosuria and improved glucose tolerance in hypothalamus-specific Pomc knockout mice. Mol Metab. 2017;6:1274-85. https://doi.org/10.1016/j.molmet.2017.07.005.

Chinushi M, Izumi D, lijima K, Suzuki K, Furushima H, Saitoh O, et al. Blood pressure and autonomic responses to electrical stimulation of the renal arterial nerves before and after ablation of the renal artery. Hypertension. 2013:61:450-6. https://doi.org/10.1161/HYPERTENSIONAHA.111.00095.

DiBona GF. Neural control of the kidney: functionally specific renal sympathetic nerve fibers. Am J Physiol Regul Integr Comp Physiol. 2000;279:R1517-24.

DiBona GF, Kopp UC. Neural control of renal function. Physiol Rev. 1997;77:75197.

DiBona GF, Sawin LL. Effect of renal nerve stimulation on $\mathrm{NaCl}$ and $\mathrm{H}_{2} \mathrm{O}$ transport in Henle's loop of the rat. Am J Phys. 1982;243:F576-80.

DiBona GF, Sawin LL, Jones SY. Differentiated sympathetic neural control of the kidney. Am J Physiol- regulatory integrative comp. Physiol. 1996;271:R84-90.

Esler MD, Krum H, Sobotka PA, Schlaich MP, Schmieder RE, Böhm M, et al. Renal sympathetic denervation in patients with treatment-resistant hypertension (the Symplicity HTN-2 trial): a randomised controlled trial. Lancet. 2010;376: 1903-9. https://doi.org/10.1016/S0140-6736(10)62039-9.

Famm K, Litt B, Tracey KJ, Boyden ES, Slaoui M. A jump-start for electroceuticals. Nature. 2013;496:159-61.

Gal P, de Jong MR, Smit JJJ, Adiyaman A, Staessen JA, Elvan A. Blood pressure response to renal nerve stimulation in patients undergoing renal denervation: a feasibility study. J Hum Hypertens. 2015;29:292-5. https://doi. org/10.1038/jhh.2014.91

García-Pérez L-E, Alvarez M, Dilla T, Gil-Guillén V, Orozco-Beltrán D. Adherence to therapies in patients with type 2 diabetes. Diabetes Ther. 2013;4:175-94. https://doi.org/10.1007/s13300-013-0034-y.

Hermansson K, Larson M, Källskog O, Wolgast M. Influence of renal nerve activity on arteriolar resistance, Ultrafiltration Dynamics and Fluid Reabsorption. Pflugers Arch. 1981;389:85-90.

Herrera MF, Toouli J, Kulseng B, Brancatisano R, Kow L, Pantoja JP, et al. Vagal nerve block for improvements in glycemic control in obese patients with type 2 diabetes mellitus: three-year results of the VBLOC DM2 study. J Diabetes Obesity. 2017;4:1-6.

lyer MS, Bergman RN, Korman JE, Woolcott OO, Kabir M, Victor RG, et al. Renal denervation reverses hepatic insulin resistance induced by high-fat diet. Diabetes. 2016;65:3453-63.

Joseph L, Butera RJ. Unmyelinated Aplysia nerves exhibit a nonmonotonic blocking response to high-frequency stimulation. IEEE Trans Neural Syst Rehabil Eng. 2009;17:537-44.

Joseph L, Butera RJ. High-frequency stimulation selectively blocks different types of fibers in frog sciatic nerve. IEEE Trans Neural Syst Rehabil Eng. 2011;19: $550-7$.

Khunti K, Wolden M, Thorsted BL, Andersen M, Davies MJ. Clinical inertia in people with type 2 diabetes. Diabetes Care. 2013;36:3411-7.

Kilgore KL, Bhadra N. Reversible nerve conduction block using kilohertz frequency alternating current. Neuromodulation. 2014;17:242-55.

Krames E, Peckham PH, Rezai A. Neuromodulation. 1st ed: Academic Press; 2009.

Krum H, Schlaich M, Whitbourn R, Sobotka PA, Sadowski J, Bartus K, et al. Catheter-based renal sympathetic denervation for resistant hypertension: a multicentre safety and proof-of-principle cohort study. Lancet. 2009;373: 1275-81. https://doi.org/10.1016/S0140-6736(09)60566-3.

Lew KN, Wick A. Pharmacotherapy of type 2 diabetes mellitus: navigating current and new therapies. Medsurg Nurs. 2015;24:413.

Liang Y, Arakawa K, Ueta K, Matsushita Y, Kuriyama C, Martin T, et al. Effect of Canagliflozin on renal threshold for glucose, Glycemia, and body weight in normal and diabetic animal models. PLoS One. 2012;7:e30555.

Luff SE, Hengstberger SG, McLachlan EM, Anderson WP. Distribution of sympathetic neuroeffector junctions in the juxtaglomerular region of the rabbit kidney. J Auton Nerv Syst. 1992;40:239-54.
Madhavan M, Desimone CV, Ebrille E, Mulpuru SK, Mikell SB, Johnson SB, et al. Transvenous stimulation of the renal sympathetic nerves increases systemic blood pressure: a potential new treatment option for Neurocardiogenic syncope. J Cardiovasc Electrophysiol. 2014;25:1115-8. https://doi.org/10.1111/ jce. 12466.

Maeda S, Kuwahara-Otani S, Tanaka K, Hayakawa T, Seki M. Origin of efferent fibers of the renal plexus in the rat autonomic nervous system. J Vet Med Sci. 2014;76:763-5. https://doi.org/10.1292/jvms.13-0617.

Mahfoud F, Edelman ER, Böhm M. Catheter-based renal denervation is no simple matter: lessons to be learned from our anatomy? J Am Coll Cardiol. 2014;64: 644-6. https://doi.org/10.1016/j.jacc.2014.05.037.

Mahfoud F, Schlaich M, Kindermann I, Ukena C, Cremers B, Brandt MC, et al. Effect of renal sympathetic denervation on glucose metabolism in patients with resistant hypertension: a pilot study. Circulation. 2011;123:1940-6. https://doi.org/10.1161/CIRCULATIONAHA.110.991869.

Mather A, Pollock C. Glucose handling by the kidney. Kidney Int. 2011;79(Suppl 120):S1-6. https://doi.org/10.1038/ki.2010.509.

Miki K, Kosho A, Hayashida Y. Method for continuous measurements of renal sympathetic nerve activity and cardiovascular function during exercise in rats. Exp Physiol. 2002;87:33-9.

Muller J, Barajas L. Electron microscopic and histochemical evidence for a tubular innervation in the renal cortex of the monkey. J Ultrastruct Res. 1972;41: 533-49.

Pan T, Guo J, Teng G. Renal denervation, a potential novel treatment for type 2 diabetes mellitus? Medicine (Baltimore). 2015;94 https://doi.org/10.1097/MD. 0000000000001932.

Patel YA, Butera RJ. Differential fiber-specific block of nerve conduction in mammalian peripheral nerves using kilohertz electrical stimulation. J Neurophysiol. 2015;113:3923-9. https://doi.org/10.1152/jn.00529.2014.

Phillips RA, Hamilton PB. Effect of 20,60 and 120 minutes of renal Iscemia on glomerular and tubular function. Am J Phys. 1948;152:523-30.

Polonsky W, Henry R. Poor medication adherence in type 2 diabetes: recognizing the scope of the problem and its key contributors. Patient Prefer Adherence. 2016;10:1299-307. https://doi.org/10.2147/PPA.S106821.

Pontes RB, Crajoinas RO, Nishi EE, Oliveira-Sales EB, Girardi AC, Campos RR, et al. Renal nerve stimulation leads to the activation of the $\mathrm{Na}^{+} / \mathrm{H}^{+}$exchanger isoform 3 via angiotensin II type I receptor. Am J Physiol Ren Physiol. 2015; 308:F848-56. https://doi.org/10.1152/ajprenal.00515.2014.

Rafiq K, Fujisawa Y, Sherajee SJ, Rahman A, Sufiun A, Kobori H, et al. Role of the renal sympathetic nerve in renal glucose metabolism during the development of type 2 diabetes in rats. Diabetologia. 2015;58:2885-98. https://doi.org/10.1007/s00125-015-3771-9.

Sabaté E. Adherence to long-term therapies: evidence for action. Geneva: World Health Organization; 2003.

Sakakura K, Ladich E, Cheng Q, Otsuka F, Yahagi K, Fowler DR, et al. Anatomic assessment of sympathetic Peri-arterial renal nerves in man. J Am Coll Cardiol. 2014:64:635-43.

Seufert J. SGLT2 inhibitors - an insulin-independent therapeutic approach for treatment of type 2 diabetes: focus on canagliflozin. Diabetes Metab Syndr Obes. 2015;8:543-54.

Sohtell M, Karlmark B, Ulfendahl H. FITC-inulin as a kidney tubule marker in the rat. Acta Physiol Scand. 1983;119:313-6.

Stocker SD, Muntzel MS. Recording sympathetic nerve activity chronically in rats: surgery techniques, assessment of nerve activity, and quantification. Am J Physiol Heart Circ Physiol. 2013;305:H1407-16. https://doi.org/10.1152/ ajpheart.00173.2013.

Toto RD. Conventional measurement of renal function utilizing serum creatinine, creatinine clearence, inulin and Para-aminohippuric acid clearance. Curr Opin Nephrol Hypertens. 1995;4:505-9.

van Amsterdam WAC, Blankestijn PJ, Goldschmeding R, Bleys RLAW. The morphological substrate for renal denervation: nerve distribution patterns and parasympathetic nerves. A post-mortem histological study. Ann Anat. 2016;204:71-9. https://doi.org/10.1016/j.aanat.2015.11.004.

Van Vliet BN, Smith MJ, Guyton AC. Time course of renal responses to greater splanchnic nerve stimulation. Am J Physiol. 1991;260:R894-905.

Walter SJ, Zewde T, Shirley DG. The effect of anaesthesia and standard clearance procedures on renal function in the rat. Q J Exp Physiol. 1989;74:805-12.

Wilding JPH. The role of the kidneys in glucose homeostasis in type 2 diabetes: clinical implications and therapeutic significance through sodium glucose co-transporter 2 inhibitors. Metabolism. 2014;63:1228-37. https://doi.org/10. 1016/j.metabol.2014.06.018. 
Witkowski A, Prejbisz A, Florczak E, Kadziela J, Šliwiński P, Bieleń P, et al. Effects of renal sympathetic denervation on blood pressure, sleep apnea course, and glycemic control in patients with resistant hypertension and sleep apnea. Hypertension. 2011;58:559-65.

Woodbury DM, Woodbury JW. Effects of vagal stimulation on experimentally induced seizures in rats. Epilepsia. 1990;31(Suppl 2):S7-19.

Yao Y, Fomison-Nurse IC, Harrison JC, Walker RJ, Davis G, Sammut IA. Chronic bilateral renal denervation attenuates renal injury in a transgenic rat model of diabetic nephropathy. AJP Ren Physiol. 2014;307:F251-62. https://doi.org/ 10.1152/ajprenal.00578.2013.

Zanchetti A, Stella A, Golin R, Genovesi S. Neural control of the kidney - are there Reno-renal reflexes? Clin Exp Hypertens. 1984;6:275-86.

Ready to submit your research? Choose BMC and benefit from:

- fast, convenient online submission

- thorough peer review by experienced researchers in your field

- rapid publication on acceptance

- support for research data, including large and complex data types

- gold Open Access which fosters wider collaboration and increased citations

- maximum visibility for your research: over $100 \mathrm{M}$ website views per year

At BMC, research is always in progress.

Learn more biomedcentral.com/submissions 